\title{
Information technology for persons with a disability: A vision for the International Federation for Information Processing
}

Geoff Busby*, MBE and Diane Whitehouse** * British Computer Society Disability Group, c/o GEC Computer Services Limited, Great Baddow, Chelmsford Essex CM2 8HN, United Kingdom Tel: +44 1245 242950, Fax: +441245 478317 ** PhD Programme London Business School, Regent's Park, London NW1 4SA, United Kingdom Tel: +441712625050 X3646, Fax: +441717247875

Email:dwhitehouse@lbs.lon.ac.uk

\begin{abstract}
For the information technology industry, there is considerable potential in developing information and communication technologies that can enhance the lives of people with a disability (who number over 500 million worldwide).

Information and communication technologies can offer many different and creative solutions to the needs of persons with a disability: they can enable increased social citizenship, culture, democracy, and equality of access. But the kinds of technologies that are useful to people with a disability are also of use to society as a whole. Designing for all kinds of people, whether able-bodied or disabled, is simply good design. To create this change in perception, we need to work with positive images of disabled people and to influence the attitudes of computer scientists, systems designers and developers, and information and communications specialists.

Where does the International Federation for Information Processing fit in to such an approach? As an international federation of professional computing associations, it can take many constructive and progressive actions. Among these, it can promote the best practice of a few computer societies; it can extend its own
\end{abstract}


position on equality of access; it can help in changing perceptions; it can act as a facilitator for consumers' needs; it can lead the world community in terms of IT values; and it can act as a watchdog, creating awareness of the social implications of information and communication technologies for the use of all people, including people with a disability. It is in this latter area particularly that potential, future directions for IFIP's Technical Committee 9 lie. It is here that the paper places its emphasis.

\section{INTRODUCTION}

The International Federation for Information Processing (IFIP) has considerable potential for influencing the kinds of information and communication technologies (ICT) available to the public at large, and disabled users specifically. Within this context, it is particularly important that IFIP's Technical Committee (TC) 9 researches the social implications and the social consequences of ICT in general and for persons with a disability especially. TC9 is potentially IFIP's interface between society and technology. TC9 could really help the information technology (IT) industry and profession in this area, showing information technologists how to be socially conscious, to know what technologies are available, and what the social reasons for this are.

The paper highlights potential, future directions for IFIP's TC9, using disability issues as an example. We have chosen this particular focus because, as individuals involved in and active in this field, this is our own personal area of concern. Hence, the paper emphasizes the interface between information and communication technologies and disability.

The paper does not specify a particular strategy for IFIP. Rather, the paper's intention is to focus on a vision for IFIP; it assumes that visions and values must enter the daily lives of organizations (Kanter, 1990). It focuses on the kind of vision that is often seen as prefacing an organization's mission, aims, and objectives (Bryson, 1988; Smith, 1995). At a later stage of preparation and planning, exact times, dates, places, and precise actions can be discussed.

Nor does the paper concentrate on any one specific disability but rather it deals with a range of disabilities. Its intention is to raise readers' general levels of awareness rather than to detail the conditions of a single impairment. (Indeed, some impairments - cerebral palsy, for example - often involve multiple incapacities.) The paper also assumes that disability is neither fixed nor absolute; it is not a condition in its own right nor the result of a personal limitation; and it has very little to do with the body. Rather, disability is a social construct (Oliver, 1989; Barton, 1996; Hales, 1996; Oliver, 1996).

The paper's aim is to put ability issues on the agenda so that individuals and groups become aware of the issues at stake, perceptions are changed so that disability is taken into account during the design process and, as a result, disabled people begin to have the IT tools available to them to facilitate their greater knowledge and to enable their greater access into the community and society. The paper's message is that universal design is do-able.

The paper first examines these concerns by giving an overview of the potential for user participation and involvement of persons with a disability. It later reviews 
contemporary figures relating to the numbers of people with a disability worldwide, the case for designing IT for people with a disability and using IT more, and commonly-held perceptions of disabled people including media and marketing examples. It then turns to assess what actions IFIP can take to improve attention to this field, and what TC9 specifically can do. Throughout the paper run the themes of culture and democracy in a global world.

\section{CULTURE, DEMOCRACY, USER PARTICIPATION AND INVOLVEMENT OF PERSONS WITH A DISABILITY}

Information and communication technologies can provide the potential for increased citizenship, culture, and democracy to persons with a disability. What society provides should be accessible to all. Attention needs to be paid to the full participation of disabled people in society, their complete access and involvement, and the diversity of cultures that result. IT can particularly offer to people with a disability increased access to schooling, further and higher education, employment, housing, leisure, lifestyle, welfare, culture, politics and decision-making.

Here we take culture to mean that which enables each and every one of us to master our own destiny (Berleur, 1994 citing Touraine, 1984). For us, therefore it means equality of access. People need to have an understanding and knowledge of information and communication technologies in order to increase and expand their own potential use of these technologies; this is as true for people with a disability as it is for able-bodied people. It is considered to be among the intellectual and moral responsibilities of computer scientists and information and communication technology practitioners to make information and technology comprehensible (Berleur, this volume). Indeed, a wider range of communications may need to be used when explaining information and communication technologies to people who have a disability (for example, drawings and pictures, short words and sentences, tapes, photos, symbols, sign language, or deaf-blind communication) (Change, $\mathrm{n} / \mathrm{d}$ ). Care and attention also needs to be paid to involving people with a disability in the design process of information and communication technologies. There needs to be real understanding and knowledge in order to control IT. It is this growing awareness which will help people with a disability to shape their own destinies. People with disabilities are part of the social tapestry; having them present, visible, and participating is tremendously important for the richness of the embroidery of social citizenship. It is through talking about their experiences, their circumstances, their understanding, and their culture that disabled people - like all other communities - can share in what is common to us all (Berleur, 1994).

More user involvement in design and needs assessment is required. Currently, many disabled people are not allowed to choose the most appropriate technologies for their requirements: whether, so to speak, they require a Mini Minor or an Alfa Romeo. Technologies are imposed on them; they are not allowed to ride their own wheels or to turn their own machines on or off. In a more democratic world, these are the kinds of tasks that disabled people ought to be able to do for themselves.

Democracy implies the capacity to participate fully in voting, in polling, and other forms of decision-making as well as running for office and taking up political positions. This participation in the community or society is as important for 
people with a disability as it is for able-bodied people. Some important British examples of disabled people involved in national politics include eminent politicians such as Lord Jack Ashley, David Blunkett, and Emma Nicholson. Each of these individuals who has a particular disability has developed longstanding political careers, held important political portfolios, and initiated prominent legislative developments.

In the potential opening-up of electronic democratic spaces, care needs to be taken that these spaces are open and available to persons with a disability. Communications are all-important so that persons with a disability know what the available methods and political procedures are. It is also important that research into the innovative possibilities offered for election and voting procedures by such new technologies as the Internet also consider the precise circumstances of access and involvement of individuals with a disability. Many different forms of access may need to be considered because disabilities can be many, various, and even multiple. And, of course, the numbers of disabled people worldwide are enormous.

\section{THE GLOBAL PERSPECTIVE ON PERSONS WITH A DISABILITY AS POTENTIAL MARKETS}

There are tremendous opportunities offered to information technology (IT) manufacturers and developers in terms of persons with a disability as a market for IT. In Britain alone, the number of people with a disability is estimated at 6 million by the general household survey (FEFC, 1996, p7), a figure which does not include the elderly at large. Recent figures indicate that disabled British individuals have an annual disposable income of over $£ 33$ million. There are an estimated 33 million people with a disability in Europe and around 50 million in the United States (The Economist, 1996).

Even though there are few international studies, we should not forget the massive numbers of persons with a disability in developing and newly developed countries. Disabled people live in all the countries of the world, and particularly detailed studies of their conditions have been undertaken in India, Jordan, the Occupied Territories, the Lebanon, Zanzibar, and Zimbabwe (Coleridge, 1993). In China, for example, there may be as many as 50 million disabled people (Ming, 1993).

Although the figure is disputed, one estimate of the total world population puts the number of disabled people at approximately 500 million, so that perhaps ten per cent of the world's population has either a permanent or a temporary physical, sensory, or mental impairment (Despouy, 1991). Surrounding the disabled too, there is also their cultural community, and their carers. In addition, the new wave of the elderly is as yet unquantifiable (Age Concern, 1996; BrowerJanse, Maddy D. et al., 1997). In some sense, we are all only temporarily ablebodied (TAB).

At a global level, it is often those from the wealthiest backgrounds who have access to IT; too often it is the children of the wealthy, for example, who are in special schools or at special centres. In Britain, attention is paid to insufficient IT equipment in deprived areas such as southeast London, Liverpool, or Glasgow but, 
if these areas have problems, what about the global dearth of IT for people with disabilities, in continents like Africa, Asia or southern America?

In these figures lies a global, multicultural, challenge; indeed, a global, multicultural opportunity. Enormous numbers of disabled people could be helped by IT. Clearly, there are plenty of possibilities for marketing good, well-designed products to persons with a disability. In all contexts, the question to be asked of people in the IT industry is: are your products geared up and designed to appeal to this expanding community?

\section{The case for IT for persons with a disability}

What is good design? Good design is commonsense - it's that simple. Why is good design commonsense? Good design is commonsense because:

- it serves potential markets

- it serves the community

- it makes a better product

- it opens up new areas of technology

- it allows consumers to look at technology from a new perspective.

Design that designs for all sorts of people, able-bodied and disabled, is simply good design. Good design of information and communication technologies matters to us all because we are all only temporarily able-bodied (TAB). In reality, the differences between disabled and able-bodied people are minute, and large numbers of people become disabled as they age.

It is this kind of enhancement to the lives of people through the new information and communications technologies that can improve citizenship, culture, and democracy (Berleur, this volume). Good design would produce a better world, one that is more integrated and more multicultural.

Within this general context, two pieces of recent legislation are of particular importance: the United States' Americans with Disabilities Act (ADA) (1990) and the British Disability Discrimination Act (DDA) (1995). The implications of these laws require greater research but this is not the focus of this paper, and these issues have been more adequately covered elsewhere (for example, Gooding, 1994).

One example of good, new design of information and communication technologies is telecommunications. Its affordances offer considerable improvements to users with difficulties in hearing, speech, sight, mobility, or dexterity. For example, for people with quiet or with no voices, British technologies such as Claudius II or Ferntech 320, telephones which 'speak' recorded phrases or which allows users to make calls unaided using a single switch, are invaluable (British Telecommunications plc, 1996). Similarly, the Deaf and Disabled Telecommunications Program of the California Public Utilities Commission provides new speech-to-speech services facilities for those who have a quiet voice or who have no voice (Interactions, 1996).

The economics of taking good preventative measures are also very important: good design can have a huge impact economically. Good design can help avoid many disabling conditions, like repetitive strain injury (RSI) where it is keyboards and mice that often cause injuries. Information technology goods and equipment need to be designed so that they do not cause damage. Good design will then spread and will become available to everyone, able-bodied and disabled alike. 
Well-designed information and communication technologies can help produce a better society and help designers not to be destructive in the human sense. Can the IT industry afford not to take action?

\section{Why we need to use IT more}

Technology is keeping more and more people alive, including many people with a disability. For example, the numbers of people with a severe learning disability is growing. In Britain alone, there are currently 50,000 people with a severe learning disability aged between 25-34 years old, and 30,000 between the ages of 35-44. Increasingly, such individuals are living until much older ages, often until age 60 or more (Mental Health Foundation, 1996).

Yet, at the same time, we are not using information and communications technologies enough. Many technologies are still under-used. The technologies that are available could be used much more in a quality way to help the rapidly expanding community of disabled persons. The dichotomy is that, while more disabled people may be alive, their everyday lives in the community may prove to be a difficult struggle.

Of course, there are dangers for disabled people in the new information and communication technologies, particularly in terms of possible social exclusion (Whitehouse, 1993), but then there are dangers for everyone. Rather, there are possibly even more opportunities for disabled people for access and communication than they would have had otherwise.

Technologies in general can offer so many opportunities to disabled people. Take the provision of television subtitles: simply having subtitles can make watching the television into a much more enjoyable experience for a person who is tone deaf. Or announcing railway station or bus-stop names over the loudspeaker: this can make an all-important difference to the travel journey for someone who is blind or someone who cannot read very well. Technology can also offer selfsupport, control, and security systems for people with a disability (Mangan, 1993, p49). It can enable users to activate or de-activate security alarms, dial up to one hundred numbers on the telephone, open and shut curtains, or turn the television on or off.

In Britain, for example, community care is now available (HMSO, 1990). However, carers are often only interviewed once and that is the extent of their training. A lot of carers have never come into contact with people with a disability or with elderly people before. Carers may know the standard answers in a given situation but apparently they do not know what to do in an emergency. Carers need to have quick and easy access to a source of expertise, just like para-medics in the middle of Africa. This could be done by making CD-Roms or online communication available to them. Imagine you are a carer and you have a portable computer or a laptop computer with you, or access to a CD-Rom, you would be able to follow a quick lesson on how to set up and use a hoist, for example, if you needed it.

Another example is that the educational ethos of the three Rs (reading, 'riting, and 'rithmetic) still dominates. Yet, in ten years' time, people may not need to read or write: people will just be able to speak and a machine will respond. Not everyone will need to be a mathematician. Education will have to change because 
information and communication technologies will increasingly do a lot that people currently have to do for themselves intellectually.

Information and communication technologies can offer creative solutions to the needs of people with disabilities. If we take the example of learning difficulties, we can cite the exploration of such technologies as talking screen and sentence scanning software, symbol systems, wide ranges of switches (for example, large, sensitive, flat switches), letter grids, concept keyboards, visual stimulation systems, vibration systems using music tapes and cuing music, audio-visual interaction systems, and virtual reality systems to enhance the learning abilities and lives of children, young adolescents, and mature adults with learning disabilities (Ability, 1997).

Increasingly, the relationship between the television, telecommunications, and the computer will become seamless. It will become chips with everything. Artificial intelligence, virtual reality, the information highway, multimedia, broadband communications, and CD-Rom technology: these are the kinds of technologies that can be useful to people with a disability.

But these are not just technologies that are useful to people with disabilities; they are also useful to society as a whole. Take for example, the Internet. It is no longer in the hands of IT specialists. It used to seem weird when people communicated with each other using computers; now it is becoming more and more common. People are increasingly surfing the Internet as part of their leisure activities. Like cable television, the use of the Internet will become more and more widespread (Kehoe, 1996).

To sum up, the kinds of technologies that are useful to people with disabilities are useful to society as a whole. They make using information and communication technologies easier and more accessible to all.

\section{PERCEPTIONS OF PERSONS WITH A DISABILITY}

What are your personal perceptions of persons with a disability? Disability is more of a social perception than a medical status (Oliver, 1996). A distinction needs to be made between what is medical and what is social. Look at the kinds of words used to describe someone who has a disability: for example, they are said to be 'suffering from' a particular 'handicap' or are 'wheelchair bound'.

Images of disabled children get over-used. Disabled children are presented as objects, and the associated messages are very patronising. Images of disabled children are accompanied by the message, 'Give, give, give, to help these poor children.' But they are not poor children. The message really ought to be: if a person cannot drive a car, they may simply need to be given a lift. This is the kind of insight that is very important for IT designers.

When IT people think of persons with a disability, all too often they think of those who are partially sighted or blind. Why is that so? Partly because visual difficulties are culturally easier to accept and partly because they are easier to handle in the sense of being a well-defined problem.

There are currently many advances in the fields of computer engineering, opthamology, and biology. These sciences are collaborating to bring sight to the vision-impaired through electronic prostheses; specialized image-processing cells; 
ocular implants; semi-conductor technology, and computational neural networks (IEEE, 1996).

Why is Stephen Hawking shown on Star Trek, for example? He is used to send out a message about people with disabilities; he focuses the public's attention on the capacity of technology to improve lives (Smith, 1994).

With all Geoff Busby's qualifications, he too is caught in much the same conundrum: he is also used to send out a message. But Geoff just wants to do his job. He hates it when strangers become interested in the fact that he is married, or that he has children, or assume that, because he works with computers or has an MBE, he must be brilliant. He is not a bitter person because he is disabled and because he has cerebral palsy. He has his good times and he has his bad, but he enjoys his work and using the gifts and abilities that he has been given. For Geoff, it is a huge bonus that he can do the work he does and that he can use the gifts in his possession.

So, people at large need to think in terms of new images of the disabled. Designers need to consider people's abilities and disabilities. What can people do and what can they not do? People need to start considering each other's needs. What would information technology have meant, for example, to the Irish poet and author, Christy Brown, whose early life was portrayed in the feature film, My Left Foot?

What kinds of images do persons with a disability have of themselves? Ask a person who has no verbal communications what his or her aspirations are. Then give him or her a portable computer and a voice synthesizer. See what kind of effect that can have. Using a voice synthesizer, for example, can be crucial. For the thousands of people who cannot speak, this application alone can help enormously. Voice chips cost peanuts, so they should be on standard offer in IT equipment.

What communication means to you and what it means to someone else can be very different. For example, for Geoff Busby who uses a voice synthesizer, it means he can put his ideas across in a voice which, while he knows it is not his own, is at least comprehensible to the audience. Geoff enjoys customizing his 'voice' by adding his own idiosyncratic speech patterns as well as adding humorous cartoons to his presentations. Because his own, physical, voice is no longer exhausted, Geoff can also add spontaneous quips or jokes to his presentations, and the audience is able to understand these clearly. For Geoff, communication also means gaining more access to information that he needs. He hopes to do far more of this in the future through the use of CD-Roms, satellites, videos, and web technology. $\mathrm{He}$ is optimistic that progress in this particular technological domain will mean that he will no longer have to visit specialized broadcast studios to undertake such tasks.

Another British Computer Society Disability Group (BCS DG) colleague, Ken Stoner, founder of the IT can Help project, explains what communication means to him. Ken has had motor neurone disease for ten years and lost his voice and handwriting ability seven years ago. He says that life would be a very sad affair without his computers. Ken's wheelchair-mounted laptop synthesizer means he can join in any conversation, give long presentations or lectures, and tell jokes in the pub without forgetting the punch lines (he has input the lines in memory). Ken's desktop computer and laser printer allow him to carry on with his voluntary work for people with disabilities, for example through the IT can Help network, which 
would not otherwise be possible. In this way, Ken continues to make an extremely valuable contribution to his community.

For Diane Whitehouse, technology means the opportunity to communicate and correspond with colleagues at a distance, regionally, nationally, and internationally. It means being able to work more easily on collaborative projects.

To sum up, it is particularly important for IT designers and systems personnel not to limit their perceptions of individuals with a disability. They need to overcome the legacy of negativism that surrounds disabled people; they need to see people as people (Nelson, 1994). Information technology designers need to consider users' abilities and disabilities. It is important for the computer industry to be flexible in analyzing and assessing people's information and communication technology needs. The way forward is to consider designing for all, and incorporating all needs and abilities.

\section{Media and marketing images of persons with a disability, erotica and pornography}

In Britain, at least on television, there is what is called the 'nine o'clock watershed'. Certain sexual or violent images can only be shown on television after nine at night. The television viewer has the choice of keeping the television channel on or switching it off. But what if that viewer cannot turn the television on or off him or herself?

Many people gasp when the word pornography is mentioned. Yet information and communication technologies, multimedia, and virtual reality can help satisfy the social, emotional, and even sexual needs of people with disabilities. Electronic pornography is one form of access some people with disabilities have to 'love'; telecommunications may be the only means of communication, sensitivity, and chitchat that some disabled people have.

Advertising, however, is often overlooked, and much advertising has a sexual content. Marketing experts use sexual images for advertising purposes, and it seems to work: if the images did not work, and if people did not succumb to marketing messages, marketing firms would not use them. So, in a way, individuals with a puritanical attitude make some sense when they say that titillating images have an effect. Western society is, however, hypocritical because some of its members object to explicit erotica or pornography while many sales and marketing techniques are based on implicitly sexual imagery.

Information and communication technologies and interactive media, television, CD-Roms, and the Internet, are all bringing to audiences and consumers sexual imagery. While spectators watch an apparently intellectual television programme, suddenly the advertising bombards them with sexual images. Pornography comes looking for the audience rather than the audience having to look for it.

The images used in commercials and in advertising can be just as 'dangerous' as pornography: they offer misleading, unrealistic, overly perfect images of what people are, what realistic role models are, and what life is: images that can be very offensive to disabled people. These images can be found on television programmes such as Baywatch, on the Internet, on pop videos or in the lyrics of pop records. They project stereotypes in a world in which all women have a wonderful figure 
and all men have a 40 " chest: of course, very few individuals live up to these perfect images.

People with disabilities now send out messages. From the early 1990s onward, there has emerged a whole new awareness, susceptibility, and perception (Nelson, 1994) ${ }^{1}$. More enlightened marketing companies are introducing people with disabilities in advertising in a positive manner. For example, the North American markets feature participants in the ParaOlympics who advertise sports gear. Good-looking disabled people are now sell swimming costumes. In television adverts advertising swimwear, the camera will eventually pull back at the end of a shot, to show only then that the attractive, champion male swimmer in the pool is a wheelchair user: a sort of shock tactic, but a useful and positive tactic. People with disabilities now star on stage and on screen in positive, nonpatronising plays, films, and television programs. Media forums on disabilities are being set up in countries like Britain to examine best codes of practice for the portrayal of persons with disabilities in various media.

To sum up, information technologists should not impose a particular code of ethics on to people with regard to pornography; they should not set themselves up as God. There is a risk that information technologists will go too far in mandating certain behaviours, or in being overly 'ethical'. Information technologists should not take orthodox frameworks and impose them on whole communities of people. Globally, there are considerable cultural differences between regions and countries in terms of what they find acceptable or not: different cultures and societies accept different norms. An identical set of judgements cannot be used for everyone. Clearly, there are attenuating circumstances that may have to be considered, especially with people with disabilities.

\section{WHERE DOES IFIP FIT IN?}

More than any other facet of advancement of modern society, the new developments in the field of information and communication technologies, such as virtual reality, artificial intelligence, and multimedia increase the potential for social citizenship, culture, and democracy to even larger numbers of people. This is especially true for persons with a disability, and particularly for disabled people in the developing countries, where there lies even greater potential. It is our role, as members of IFIP, to make sure that these new technologies are available to everyone. Our role should be to spread the word.

In the disabilities field, there are extensive opportunities for developing the IT industry that are currently not being recognized. IFIP needs to create an awareness and a vision for the IT industry to follow, particularly with regard to the blossoming new information and communication technologies such as virtual reality, multimedia, broadband communications, and telecommunications. IFIP needs to know that people with disabilities want to make use of these technologies

Some interesting examples of positive images of persons with a disability, often using information and communications technology, can be found in magazines such as Abilities, Ability Network, Disability Today, and Freedom. (These guides for the disabled and lifestyle magazines all originate in Canada. There are, of course, similar magazines in other countries.) 
in their everyday activities. Similarly, the IT industry needs to listen to its users, whoever those users are. Users are everybody; and people with disabilities want to be included in the use of information technology, not excluded.

IFIP can particularly help because it is a global, international organization with access to many different parts of the globe and many different computer societies. IFIP is an international federation of professional and technical organizations concerned with information processing, and the national groupings of these associations which has been in existence since 1960. As a federation, it is dedicated to improving worldwide communication and understanding among practitioners of every nation about the role that information processing can play in all walks of life. In a sense, IFIP is the United Nations (UN) of information and communication technologies.

IFIP could act as a facilitator of people's desires, ideas, and aspirations with regard to IT. IFIP could be the go-between or intermediary between consumers and suppliers. IFIP is in a unique position to do this; it is truly international in its reach - it is not just locked into a North American perspective.

Within IFIP, there need to be people with disabilities who can argue the case for the new disabled markets, new market awareness, new technological opportunities, and for the full realization of the potential of all people. IFIP needs to think about enhancing its leadership role: disabled people should be more visible and more involved in decision-making. (Sadly, at the moment, some people who have a disability are not able to attend certain IFIP meetings because they cannot stay in particular hotel accommodation or because the physical access to buildings is simply not there. Also, there appear to be insufficient industrial contacts within IFIP for people with disabilities to get sponsorship to attend meetings. These limitations need to be considered when organizing meetings and conferences.)

IFIP has the responsibility to explore much wider access to its members and potential members than exists currently. It can ensure that disability issues are covered as a theme in its conferences and workshops. It can ensure that all conferences, workshops, and meetings are physically accessible and have a full range of communication facilities available. It can also encourage all computer societies to have a policy or position on information and communication technologies for people with a disability and to enable the fullest possible access to all potential members. Visionaries can build accessibility into all IT products for all consumers.

Some good examples of what professional computer societies are now doing to help persons with a disability include associations in Austria, Britain, Denmark, Germany, Greece, Holland, Hungary, and soon Ireland. Computer societies considering what they might do in this area can build on the good practice illustrated, for example, by the British Computer Society Disability Group (BCS DG). Established in 1975, the BCS DG now has over five hundred members. BCS DG has a high degree of involvement at both board and volunteer levels of persons with a disability; it lobbies widely for the technology needs of persons with a disability; it liaises with other influential bodies working in this area, such as The Computability Centre; it organizes the IT Can Help project which provides free advice and assistance on technology for persons with a disability and it organizes other special projects from time to time; it is a source of information through its 
brochures, pamphlets, and meetings; and, last but not least, it publishes an informative, increasingly high-quality and high-profile magazine on the information and communication technologies available to persons with a disability.

IFIP needs to have an inspirational role, to be a leader in IT values and ethics. If IFIP can lead the IT industry in an awareness of this particular area, of the potential that can be offered by information and communication technologies to persons with a disability, it would be doing the IT industry a big favour. But IFIP should not just be a marketeer. While IFIP can act as a promoter of the potential offered by new information and communication technologies, it needs to do so in an ethical way.

IFIP needs to act in a responsible manner. It can also be a watchdog. It needs to be professional in its understanding of the social implications of the technologies being developed. For, what good are information and communication technologies if they are not designed for people, and if they are not useful to people?

\section{What about TC9?}

This is where Technical Committee (TC) 9 can especially help. TC9 can make people aware of the social implications of the information and communication technologies currently being developed, making sure that these technologies are well designed for the use of all people, including persons with a disability. It is important that the computer industry does not make the mistake of certain other design professions - such as the field of architecture which is prone to create disabilities through inappropriate design.

The culture of TC9 needs to be spread within IFIP. TC9's brief is concerned with the relationship between computers and society: it examines the influence and social consequences of IT applications on individuals, groups, and societies; it promotes social accountability; it facilitates research; it seeks to enhance the quality of life for all as a result of computer use, and to humanize the use of all information systems. Working with academics, practitioners, researchers, and users, TC9 should become the interface between society and the good design of information technology for all people, including people with disabilities.

So, TC9 can help in two principal ways: firstly, by listening to what society has to say and then feeding those findings into IFIP and, secondly, by feeding news about the new information and communication technologies out to society. TC9 can help to harmonize a global society. TC9's role could bring high-level thinkers in touch with society, helping to change their ideas about the effects of IT on societies.

TC9 can become the human interface between society and technology: showing people what the new tools are that are on offer and what the opportunities or the dangers are. It can also act as the interface with the more technical of the other TCs and working groups (WGs) within IFIP. Many of IFIP's other TCs and WGs have members who are working on completely abstract problems or technologies: they are not looking at cause and effect and pay no attention to the whole, global effects of those technologies. But TC9 is composed of experts in this field who can provide this kind of holistic view. TC9 can fill the current void; it 
can act as the go-between between information and communication technologies, society, and persons with a disability.

TC9 could investigate the various innovations and new applications that form part of the new information and communication technologies. TC9 has the expertise to say whether a particular innovation is useful or not. This kind of assessment is a social task, a social responsibility.

As members of TC9, we need to think about how to make our analyses and interpretations more internationally widespread so that they are absorbed into government policy at all levels. Society as a whole needs the kind of research that TC9 does in order to make decisions. We have to begin to analyze what are the needs of persons with a disability, what are their wants, and how information and communications technologies can enhance their lives. The facts and figures outlined in this paper, for example - ought to be hitting people in the face. So too, a good, high-profile, media event would teach people all over the world about the social effects of information and communication technologies.

TC9 could do the research, look at the potential advantages and disadvantages of specific technologies, and investigate their potential applications and implications. But we should not say that a particular technology is good or bad, because that is about playing God. (One particular weakness is that TC9 could become too judgemental - though there may be occasions on which we may actually need to take a stand.) Ideally, TC9 should simply indicate its opinions which will be, by TC9's very nature as a multicultural group, multicultural. It should be part of TC9's role to express diversity rather than to mandate a particular worldview. TC9 should be able to express the opinions of the whole world including the views of those 500 million people with a temporary or permanent disability.

\section{SUMMARY AND CONCLUSIONS}

There is considerable potential in developing information and communication technologies to enhance the lives of people with a disability, who total over 500 million across the globe. Information and communication technologies can provide many different and creative solutions to the needs of disabled people, bringing them increased citizenship, culture, democracy, and equality of access. However, the technologies that are useful to people with a disability also make important social and economic contributions to society as a whole. It is simply good design to design for all kinds of people, whether able-bodied or disabled. To create this understanding, we need to work with positive images of disabled people and to influence the attitudes of computer scientists, systems designers, systems developers, and information and communications specialists.

What is IFIP's role in this new development? As an international federation of professional computing associations, IFIP can start many constructive, progressive initiatives. Among these, it can promote best practice among computer societies worldwide; it can examine its own position on equality of access; it can help in changing perceptions; it can act as a facilitator of consumers' needs; it can lead the world community in terms of a new culture and democracy of IT values; and it can act as a watchdog, creating awareness of the social implications of information and 
communication technologies for the use of all people, including people with a disability. Of all IFIP's technical communities, TC9 ought in particular to be participating in such an initiative.

\section{ACKNOWLEDGEMENTS}

The authors would like to thank Paula Goossens, Luc Goffinet, and at least two anonymous reviewers for their helpful insights into the development of this paper.

\section{REFERENCES}

Ability (1997) Tools for learning. Ability, 19. March 1997. Chelmsford: British Computer Society Disability Group (BCS DG). Guest editor: Diane Whitehouse.

Age Concern (1996) Older people in the United Kingdom. Some basic facts. August. London: Age Concern

Barton, L. (editor) (1996) Disability and Society: Emerging Issues and Insights. London \& New York: Wesley Longman Limited

Berleur, Jacques (1994) Des rôles et missions de l'Université. Namur: Presses Universitaires de Namur

Berleur, Jacques (this volume) Culture and democracy revisited in the global information society. Summary of a position paper.

British Telecommunications plc (1996) The BT guide for people who are disabled or elderly. The latest products and services to help you use the phone. London: BT plc

Brower-Janse, Maddy D.; Fulton Suri, Jane; Yawitz, Mitchell; de Vries, Govert; Fozard, James L. \& Roger Coleman (1997) User interfaces for young and old. Interactions March \& April, 4 (2), 3446

Bryson, J. (1988) Strategic Planning for Public and Nonprofit Organisations. London: Jossey-Bass

Change (n/d) Change. An organisation representing people with both a learning disability and a sensory impairment. London: Change

Coleridge, Peter (1993) Disability, Liberation, and Development. Oxford: Oxfam (UK and Ireland)

Despouy, L. (1991) Human Rights and Disability. New York: United Nations Economic and Social Council

Economist, The (1996) Disability Law. Crippling? The Economist. December 7, 1996, 37

FEFC (Further Education Funding Council) (1996) Inclusive Learning. Report of the Learning Difficulties and/or Disabilities Committee. September. Coventry: FEFC

Gooding, Caroline (1994) Disabling Laws, Enabling Acts: Disability Rights in Britain and America. London: Pluto Press

Hales, Gerald (editor) (1996) Beyond Disability: Towards an Enabling Society. London: SAGE Publications in association with the Open University

HMSO (Her Majesty's Stationery Office) (1990) National Health Service and Community Care Act. London: HMSO

IEEE (1996) Toward an artificial eye. Spectrum. May. 33 (5). New York: The Institute of Electrical and Electronics Engineers, Inc.

Interactions (1996) People with speech disabilities sought to use new telephone support service. Interactions. November/December. 3 (6), 10

Kanter, R.M. (1990) Editorial. Values and economics. Harvard Business Review. May-June. 68, 4

Kehoe, Louise (1996) California surfing could flood phone networks. Financial Times. Friday, October 25.

Mangan, Tom (1993) Overcoming disability - a UK perspective. In Computers and Society, edited by Beardon, Colin \& Diane Whitehouse. Oxford: Intellect Press, 46-52

Mental Health Foundation (1996) Building Expectations. Opportunities and Services for People with a Learning Disability. London: Mental Health Foundation

Ming, Guo (1993) Demographic features of people with disabilities in China. Disability, Handicap, and Society. 8, 207-210 
Nelson, Jack A. (1994) Broken images: portrayals of those with disabilities in American media. In The Disabled, the Media, and the Information Age, edited by Jack A. Nelson. Westport, CT: Greenwood Press, 1-17

Oliver, Mike (1989) Disability and dependency: a creation of industrial societies. In Disability and Dependency, edited by L. Barton. London: The Falmer Press, 6-22

Oliver, Mike (1996) Understanding Disability: From Theory to Practice. Basingstoke \& London: MacMillan Press

Smith, Michael R. (1994) Assistive technology and software: liberating all of us. In The Disabled, the Media, and the Information Age, edited by Jack A. Nelson. Westport, CT: Greenwood Press, 127144

Smith, R.J. (1995) Strategic Management and Planning in the Public Sector. Harlow, Essex: Longman in association with the Civil Service College

Touraine, Alain (1984) Le retour de l'acteur. Essai de sociologie. Paris: Fayard

Whitehouse, Diane (1993) Overcoming disability: An overview of social and technological developments. In Facing the Challenge of Risk and Vulnerability in an Information Society, edited by Berleur, J., Beardon, C., \& R. Laufer. Elsevier Science Publishers B.V. (North-Holland), 183196. 